\title{
OPTIMASI SHADING DEVICES RUMAH TINGGAL (STUDI KASUS : PERUMAHAN LOH AGUNG VI JATEN KARANGANYAR)
}

\author{
Maya Puspitasari, Nur Rahmawati Syamsiyah \\ Program Studi Teknik Arsitektur, Fakultas Teknik, Universitas Muhammadiyah Surakarta \\ Jl. A. Yani Tromol Pos 1 Pabelan Kartasura Sukoharjo 57102 Telp 0271-717417 \\ E-mail: maiiaciimayy@gmail.com
}

\begin{abstract}
ABSTRAK
Perkembangan perumahan saat ini sangat pesat. Banyak perumahan dibangun dengan beragam tipe dan desain. Setiap desain yang dibuat tentunya sudah memperhatikan aspek pencahayaan alami untuk penerangan ruang-ruang di dalamnya. Penelitian ini dilatarbelakangi maraknya penggunaan shading devices di perumahan, sebagai penahan panas matahari yang umumnya memiliki desain tergolong sederhana, yaitu berupa cor beton yang ditempatkan pada bagian atas jendela. Namun apakah desain itu sudah efektif sesuai fungsinya atau belum, maka penelitian ini bertujuan untuk melihat efektifitas desain shading devices yang selama ini banyak digunakan. Perumahan Loh Agung VI terpilih sebagai lokasi penelitian, dengan pertimbangan perumahan ini hanya memiliki satu tipe rumah, dengan berbagai posisi rumah terhadap arah datang matahari, sehingga sangat memungkinkan untuk dibandingkan. Metode penelitian yang digunakan adalah kuantitatif sejak pengumpulan data hingga proses analisis. Analisis menggunakan rumus solar geometry, yang mempertimbangkan sudut jatuh matahari terhadap lokasi penelitian dan waktu pengukuran. Waktu yang dipilih adalah saat panas matahari maksimal. Hasil penelitian menunjukkan bahwa shading devices yang ada di rumah-rumah Perumahan Loh Agung VI tidak efektif memberikan perlindungan terhadap radiasi matahari. Optimasi desain shading devices agar sesuai fungsi adalah berbentuk kisi-kisi, sehingga mampu mereduksi cahaya dan panas matahari.
\end{abstract}

\section{Kata kunci : orientasi bangunan; cahaya matahari; rumah tinggal; shading}

\section{PENDAHULUAN \\ Latar Belakang}

Kota Karanganyar dengan jumlah penduduk 878.588 jiwa (tahun 2011) memerlukan penyediaan sarana hunian yang terus meningkat dari tahun ke tahun, sehingga dalam mengantisipasi hal tersebut pemerintah daerah Kabupaten Karanganyar membuat beberapa kawasan untuk perumahan. Didalam penyediaan sarana hunian tersebut, pemerintah lebih menekankan pada pembangunan rumah-rumah sederhana dan sangat sederhana. Mengingat kondisi tingkat ekonomi masyarakat Karanganyar yang mayoritas masih menengah ke bawah sehingga diharapkan masyarakat akan lebih mudah untuk mendapatkan rumah dengan harga yang terjangkau (Ismoyowati, 2012).

Perumahan Loh Agung adalah salah satu perumahan di Karanganyar yang didesain oleh arsitek/perencana dalam meng- antisipasi dan mengatasi berbagai permasalahan tersebut.

Perumahan Loh Agung VI secara administratif masuk pada wilayah desa Sawahan, Kelurahan Jaten, Kecamatan Jaten, Kabupaten Karanganyar. Proyek Perumahan Loh Agung VI dibangun dan ditujukan untuk memenuhi kebutuhan perumahan warga Karanganyar, terutama masyarakat golongan menengah ke bawah, yaitu rumah type 27 dengan luas tanah $60 \mathrm{~m}^{2}$. Perumahan yang dibangun pada tahun 2012 dengan jumlah 50 unit seluruhnya sudah berpenghuni (Ismoyowati, 2012).

Perumahan Loh Agung VI termasuk kategori sederhana, namun demikian perencanaannya tetap memperhatikan unsur keindahan sekaligus kesehatan. Pencahayaan dan penghawaan alami diupayakan dapat memberikan kesehatan ruang-ruang dan penghuni di dalamnya melalui desain 
bukaan jendela dan shading devices. Desain arsitektur, termasuk juga desain jendela dan shading devices, tentunya harus memenuhi kriteria fungsi, teknis dan estetika. Secara teknis, umumnya mencari cara yang termudah untuk dibuat dan hal tersebut biasanya menjadi pertimbangan penting dalam pembangunan perumahan, karena sangat berkaitan dengan biaya pembangunan. Sedangkan aspek fungsi dan estetis menjadi aspek yang cukup diperhatikan, karena umumnya pengembang perumahan mengutamakan keindahan untuk menarik minat pembeli.

\section{Rumusan Masalah}

Desain jendela di perumahan Loh Agung VI merupakan desain yang umum ada di perumahan-perumahan yang lain, yaitu berbentuk persegiempat tinggi $1 \mathrm{~m}$, lebar $0,5 \mathrm{~m}$. Adapun shading devices berupa cor beton dengan panjang sesuai lebar jendela $0,5 \mathrm{~m}$ dan lebar shading devices $0,25 \mathrm{~m}$. Apabila diperhatikan bentuk dan ukurannya, dan pertimbangan orientasi bangunan serta sudut jatuh matahari, maka akan muncul pertanyaan:

1. Seberapa efektifkah shading devices memberikan perlindungan dari cahaya dan panas matahari?

2. Bagaimanakah desain shading devices yang baik, agar pencahayaan alami yang dibutuhkan tetap menerangi ruang, namun bisa mengurangi panas matahari?

\section{Tujuan Penelitian}

Penelitian dimaksudkan untuk mendapatkan bentuk dan dimensi shading devices yang optimal, dengan memodifikasi shading devices yang sudah ada, berdasarkan arah orientasi rumah dan sudut datang matahari.

\section{TINJAUAN PUSTAKA \\ Standar Kualitas Cahaya Alami}

Salah satu elemen bangunan yang mempunyai fungsi penting dan harus dapat merespon kondisi iklim adalah dinding. Lippsmeier (1994) menyatakan bahwa dinding bangunan berfungsi sebagai: penstabil bangunan, pelindung dari hujan, angin dan debu, radiasi matahari secara langsung, pelindung dari dingin, kebisingan, juga sebagai pengaman dari segala sesuatu yang membahayakan bagi penghuninya.
Cahaya matahari sebagai satu unsur alam yang sangat dibutuhkan manusia, adakalanya dianggap oleh manusia sebagai sesuatu yang merugikan, sehingga dinding pelingkup bangunan harus dibuat sedemikian agar tidak 'terganggu' oleh panas matahari. Dalam hal ini manusia harus bertindak bijak terhadap sumber daya alam tersebut. Suatu saat panas dan cahaya matahari dibutuhkan bersamaan, namun ada kalanya hanya cahaya yang dibutuhkan, namun panasnya dihindari. Sebagaimana prinsip pencahayaan alami, manfaatkan cahaya semaksimal mungkin dan menghindari panasnya semaksimal mungkin (Satwiko, 2004).

Terdapat beberapa faktor yang perlu diperhatikan dalam mendesain pelindung bangunan terhadap matahari, antara lain (Lippsmeier, 1994):

1. Posisi matahari (penentuan atitude dan azimuth matahari)

2. Waktu pembayangan (jam berapa saja perlindungan sinar matahari diperlukan)

3. Sudut pembayangan yang meliputi sudut bayangan horizontal dan vertikal

4. Jenis pelindung matahari disesuaikan dengan arah bukaan.

Sementara itu cahaya matahari yang akan dimanfaatkan, sebaiknya memiliki pertimbangan sebagai berikut (Lippsmeier, 1994):

1. Kuantitas cahaya (lighting level) atau tingkat kuat penerangan

2. Distribusi kepadatan cahaya (luminance distribution)

3. Pembatasan agar cahaya tidak menyilaukan (limitation of glare)

4. Arah pencahayaan dan pembentukan bayangan (light directionality and shadow)

5. Kondisi dan iklim ruang serta warna cahaya dan refleksi warna (light colour and colour rendering)

Sesuai SNI 03-2396-2001 tentang "Tata Cara Pencahayaan Alami Sebuah Gedung", bahwa pencahayaan alami siang hari dapat dikatakan baik apabila:

1. Pada siang hari antara jam 08.00 sampai dengan jam 16.00 waktu setempat, terdapat cukup banyak cahaya yang masuk ke dalam ruangan.

2. Distribusi cahaya di dalam ruangan cukup merata dan atau tidak menimbulkan kontras cahaya yang mengganggu. 
Kualitas kenyamanan pencahayaan didalam ruangan berdasarkan SNI dan Greenship, yaitu:

Tabel 1. Intensitas Cahaya Rumah Tinggal

\begin{tabular}{|l|c|}
\hline \multicolumn{1}{|c|}{ Ruang } & $\begin{array}{c}\text { Tingkat } \\
\text { Pencahayaan (Lux) }\end{array}$ \\
\hline Teras & 60 \\
\hline Ruang Tamu & $120-150$ \\
\hline Ruang Makan & $120-250$ \\
\hline Ruang Kerja & $120-250$ \\
\hline Ruang Tidur & $120-250$ \\
\hline Kamar Mandi & 250 \\
\hline Dapur & 250 \\
\hline \multicolumn{2}{|c|}{ Sumber: SNI $03-6197-200 \mathrm{III}$} \\
\hline
\end{tabular}

Greenship menyebutkan pula penggunaaan cahaya alami secara optimal mencapai minimal $30 \%$ luas lantai, yang digunakan untuk bekerja mendapatkan intensitas cahaya alami minimal sebesar 300 Lux.

\section{Lubang Cahaya Efektif}

Bila suatu ruangan mendapatkan pencahayaan dari langit melalui lubanglubang cahaya di beberapa dinding, maka masing-masing dinding ini mempunyai bidang lubang cahaya efektifnya sendiri-sendiri. Umumnya lubang cahaya efektif dapat berbentuk dan berukuran lain daripada lubang cahaya itu sendiri.

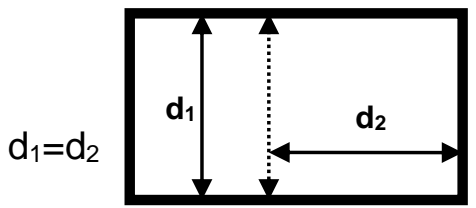

Gambar 1. Denah yang menunjukkan jarak antar dinding untuk efektifitas lubang cahaya Sumber: SNI 03-2396-2001

Kualitas pencahayaan di dalam ruangan dapat ditingkatkan, salah satunya adalah dengan penggunaan lightshelves pada fasade dinding bangunan, sebagai pemantul cahaya siang hari dari luar ke dalam ruangan. Untuk dapat memanfaatkan lightshelves dengan efektif perlu dipahami karakter pencahayaan siang hari, konteks, standar kenyamanan, permasalahan, kriteria pencahayaan yang baik dan teknologi lightshelves nya itu sendiri yang berfungsi memperbaiki atau meningkatkan kualitas pencahayaan. Lightselves yang terdapat di bagian luar dan dalam ruang, yang diletakkan di antara lubang cahaya, sangat efektif

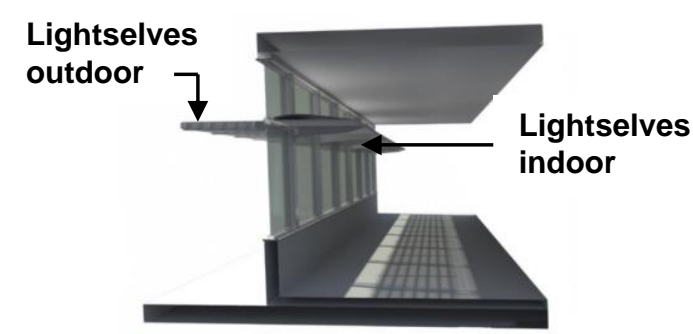

Gambar 2. Lightselves sebagai pemantul cahaya matahari

Sumber: https://firmanirmansyah.wordpress. com/category/sustainability

\section{Orientasi Matahari}

Indonesia berada di garis khatulistiwa dan beriklim tropis sehingga menjadikan variasi langit yang sangat besar. Variasi tersebut dipengaruhi oleh perubahan cuaca dan posisi matahari. Posisi matahari di bagi menjadi Equinox, Summer Solstice dan Winter Solstice.

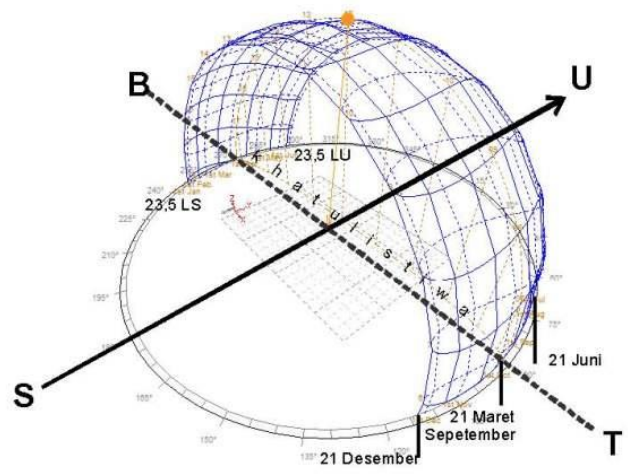

Gambar 3. Kubah langit dan kedudukan matahari Sumber: https://firmanirmansyah.wordpress.com/ category/sustainability/

Pada 21 Maret sampai 21 Desember matahari berada di sebelah Selatan khatulistiwa dengan sudut deklinasi $23.5^{\circ}$ LS sedang pada 21 September sampai 21 Juni berada di sebelah Utara Khatulistiwa dengan sudut deklinasi $23.5^{\circ}$ LU (Irmansyah, 2011).

\section{METODE PENELITIAN}

Penelitian menggunakan metode kuantitatif, sejak pengambilan data hingga analisis. Penelitian menggunakan sampel purposive, yaitu rumah-rumah yang dipilih 
berdasarkan orientasi atau arah hadap yang berbeda, dengan type rumah yang sama.

Metode pengumpulan data yang digunakan dalam penelitian ini yaitu:

1. Metode survey lapangan

Melakukan pengamatan terhadap rumah tinggal, dengan data primer berupa ukuran jendela, ukuran shading devices, serta melakukan pengukuran besarnya intensitas cahaya matahari di dalam dan di luar bangunan dengan menggunakan alat ukur luxmeter.

2. Studi Literature

Mempelajari teori-teori yang berasal dari berbagai buku, sumber data sekunder serta hasil penelitian sebelumnya yang berkaitan dengan shading devices.

Pengambilan data primer berupa pengukuran intensitas cahaya matahari berdasarkan arah hadap rumah dan waktu. Arah ke Timur pukul 08.00, arah Barat jam 15.00. Arah Utara dan Selatan diasumsikan tidak memperoleh cahaya matahari secara optimal, mengingat pengambilan data pada bulan April, sehingga posisi matahari tegak lurus ada di arah Timur dan Barat.

Arah Utara dan Selatan memiliki standar tersendiri untuk shading devices. Proporsi bidang penghalang berupa tritisan datar atau miring dalam usaha mengantisipasi sinar datang matahari untuk daerah (obyek) yang terletak antara $23,5^{\circ} \mathrm{LU}$ dan $23,5^{\circ} \mathrm{LS}$ sebagai berikut:

1. Untuk bangunan tropis yang terletak di sebelah Utara garis khatulistiwa, proporsi ideal untuk tritisan bangunan yang menghadap Utara adalah 0,3 atau $3: 1$ (rasio antara tinggi $(\mathrm{H})$ bangunan dan lebar overhang $(\mathrm{T})$, sedangkan Selatannya adalah 0,5 atau $2: 1$.

2. Untuk bangunan di Selatan garis khatulistiwa, rasionya adalah 0,3 untuk tritisan yang menghadap ke Selatan dan 0,5 untuk bangunan yang menghadap ke Utara.

Pengambilan data intensitas cahaya alami dengan luxmeter dilakukan bersamaan di dalam dan di luar ruang, untuk melihat perbandingannya dan melihat efektifitas fungsi shading devices dalam memberikan pembayangan.
Sampel purposive diambil secara acak, namun tetap memperhatikan arah orientasi. Kesamaan desain rumah memudahkan untuk analisis hingga menghasilkan desain alternatif yang dapat diadaptasi dengan mudah. Setiap arah orientasi diambil 4 sampel rumah.

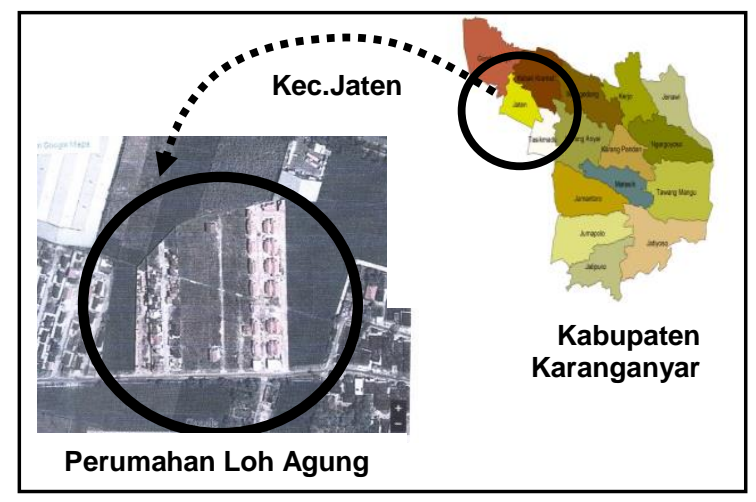

Gambar 4. Lokasi Pengamatan

Sumber: http://abjateng.net46.net/dati2.php?k= KARANGANYAR

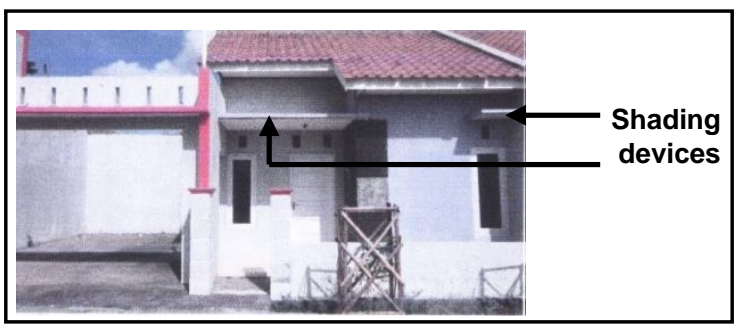

Gambar 5. Salah satu sampel rumah dan shading devices yang akan diteliti Sumber: dokumen penulis, 2014

Analisis penelitian menggunakan rumus solar geometry, untuk memastikan efektifitas shading devices yang sudah ada selama ini, serta menganalisis bentuk/desain alternatif shading devices yang dapat memberikan optimasi fungsi, berdasarkan bentuk dan ukuran jendela yang ada.

\section{HASIL PEMBAHASAN Intensitas Cahaya Matahari dan Pem- bayangan}

Pengukuran intensitas cahaya alami di sampel rumah dimulai pukul 08.00 WIB sampai dengan 15.00 WIB. Seluruh rumah menghasilkan rata-rata intensitas cahaya alami di dalam rumah dibawah 100 lux. Sedangkan standar mensyaratkan 120-250 lux. Hasil observasi mengungkap, bahwa rendahnya intensitas cahaya alami disebabkan: 
1. Pengembang menggunakan seluruh kaca jendela dengan kaca berwarna hitam.

2. Ada beberapa rumah masih menutup jendela dengan tirai.

Untuk mengetahui optimalisasi shading devices terhadap rumah-rumah maka perlu dilakukan perhitungan atau analisa untuk menemukan luasan shading devices sehingga dapat diketahui apakah shading devices di perumahan tersebut optimal atau tidak.

Fasad bangunan rumah tinggal di Perumahan Loh Agung $\mathrm{VI}$ berorientasi ke arah antara Timur Laut dan Timur $\left(\Psi=-90^{\circ}\right)$, solar azimuth $(\phi)$ adalah $20^{\circ}$

$$
\begin{aligned}
& \gamma=\Phi-\psi \\
& \gamma=20^{\circ}-\left(-90^{\circ}\right) \\
& =70^{\circ} \\
& \operatorname{TAN}(\Omega)=\operatorname{TAN}(\beta) / \operatorname{Cos}(\gamma) \\
& =\operatorname{Tan} 67^{\circ} / \cos 60^{\circ} \\
& =2,5 / 0,5 \\
& =5 \\
& \Omega=78,69 \circ \\
& =79 \text { ㅇ }
\end{aligned}
$$

Sudut jatuh matahari terhadap bangunan adalah 79 ㅇ

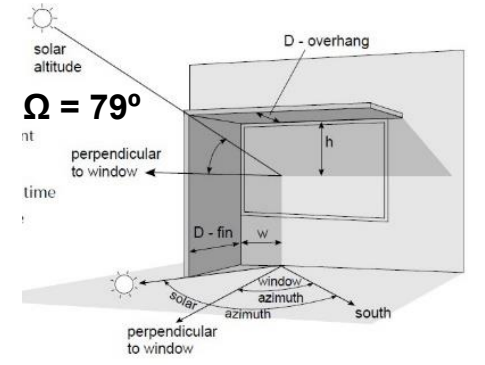

Selanjutnya menghitung lebar dan panjang shading devices.

$$
\begin{aligned}
& \mathrm{S}_{\mathrm{H}}=\mathrm{P}_{\mathrm{H}} \cdot \operatorname{TAN}(\Omega) \\
& 1,3 \mathrm{~m}=\mathrm{P}_{\mathrm{H}} \cdot \operatorname{TAN}(\Omega) \\
& \mathrm{P}_{\mathrm{H}}=1,3 / 5 \\
& \mathrm{P}_{\mathrm{H}}=0,26 \mathrm{~m}=26 \mathrm{~cm}
\end{aligned}
$$

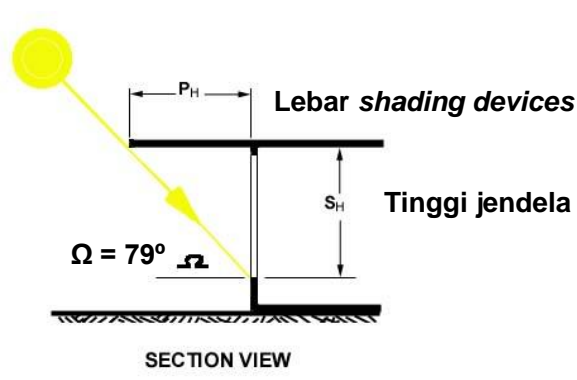

Lebar shading devices atau tritisan 26 $\mathrm{cm}$ efektif memberikan bayangan pada siang hari. Pada pagi hari fasad arah Timur pukul 08.00 masih memerlukan cahaya matahari langsung sehingga shading devices yang digunakan sudah mencukupi. Sedangkan fasad bangunan rumah tinggal berorientasi ke arah antara Barat dan Barat Daya $\left(\Psi=-90^{\circ}\right)$, solar azimuth $(\phi)$ adalah $295^{\circ}$

$$
\begin{aligned}
\gamma & =\Phi-\Psi \\
\gamma & =295^{\circ}-90^{\circ} \\
& =65^{\circ}-90^{\circ} \\
\gamma & =|-25|=25^{\circ}
\end{aligned}
$$

$$
\begin{aligned}
\operatorname{TAN}(\Omega) & =\operatorname{TAN}(\beta) / \cos (\gamma) \\
& =\operatorname{Tan} 35^{\circ} / \cos 25^{\circ} \\
& =0,7 / 0,9 \\
& =0,7 \\
\Omega & =37,8^{\circ} \\
& =38^{\circ}
\end{aligned}
$$

Pada orientasi yang berbeda, maka lebar optimal shading devices dapat diketahui:

$$
\begin{aligned}
\mathrm{S}_{\mathrm{H}} & =\mathrm{P}_{\mathrm{H}} \cdot \operatorname{TAN}(\Omega) \\
1,3 \mathrm{~m} & =\mathrm{P}_{\mathrm{H}} \cdot \operatorname{TAN}(\Omega) \\
\mathrm{P}_{\mathrm{H}} & =1,3 / 0,7 \\
\mathrm{P}_{\mathrm{H}} & =1,8 \mathrm{~m} \\
& =180 \mathrm{~cm}
\end{aligned}
$$

Tidak memungkinkan untuk membuat shading devices dengan lebar $180 \mathrm{~cm}$, sehingga perlu diselesaikan dengan menggunakan prinsip Louver Screen, yaitu berbentuk kisi-kisi, dimana cahaya matahari dapat diuraikan atau dibagi-bagi. Cara ini menjadikan silau cahaya berkurang, karena lebih banyak bidang pantul yang memberikan efek bayangan yang saling menutupi satu sama lain.

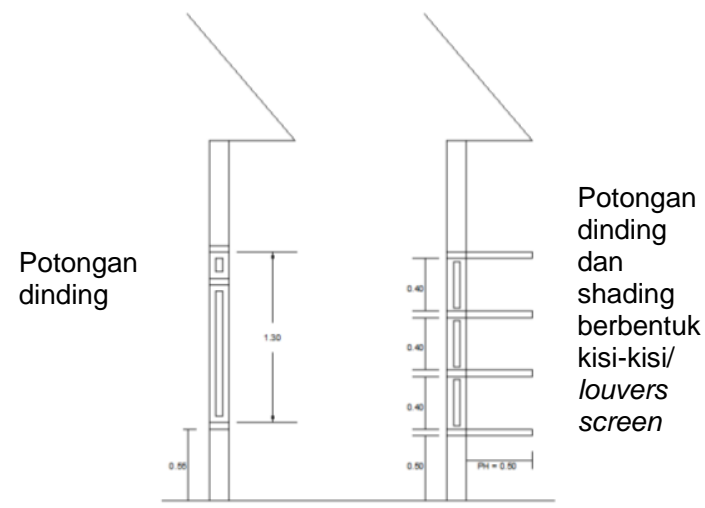

Gambar 6. Alternative penyelesaian shading devices agar optimal, dengan kisi-kisi beton Sumber: analisis peneliti 2014 
Selain menggunakan kisi-kisi beton juga bisa dengan mengurangi dimensi $\mathrm{S}_{\mathrm{H}}$-nya. Dari tinggi jendela dapat dibuat dimensi $S_{H}=40 \mathrm{~cm}$

$$
\begin{aligned}
\mathrm{S}_{\mathrm{H}} & =\mathrm{P}_{\mathrm{H}} \cdot \operatorname{TAN}(\Omega) \\
40 \mathrm{~cm} & =\mathrm{P}_{\mathrm{H}} \cdot 0,7 \\
\mathrm{P}_{\mathrm{H}} & =0,4 / 0,7 \\
& =0,5 \mathrm{~m} \\
\mathrm{P}_{\mathrm{H}} & =50 \mathrm{~cm}
\end{aligned}
$$

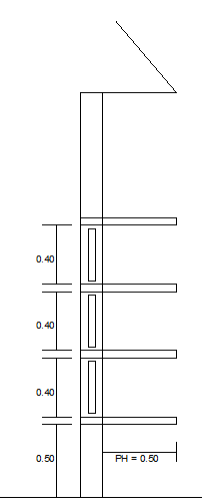

Gambar 7. Alternatif desain shading devices Sumber: analisis peneliti, 2014

Bentuk kisi-kisi pada jendela memberikan efek pembayangan yang bisa saling menutupi, sehingga bila cahaya matahari silau dan panas (misalkan pada sore hari), shading devices bentuk kisi-kisi sangat oprimal.

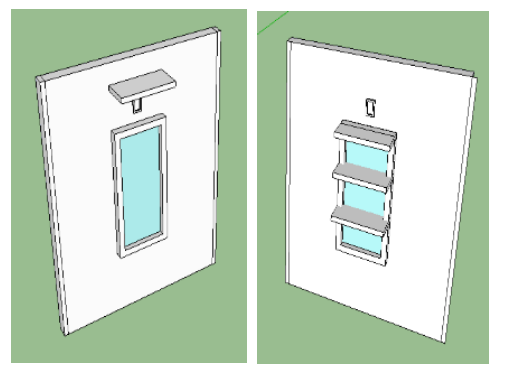

Gambar 8. Tampak shading devices asli (kiri) dan shading devices setelah redesain berdasar rumus solar geometry

Sumber: analisis peneliti, 2014

\section{KESIMPULAN}

Dimensi lebar teritisan yang ada selama ini belum memenuhi syarat kenyamanan penghuni, disebabkan kurang mampu melindungi ruang dari efek sinar matahari yang silau dan panas.

Dimensi shading devices yang ada selama ini berukuran $25 \mathrm{~cm}$, ternyata tidak mampu berfungsi optimal memberikan perlindungan atau menahan masuknya cahaya matahari yang silau dan panas.

Salah satu akibat dari penerapan desain minimalis pada rumah ini khususnya dan perumahan lain pada umumnya adalah minimnya dimensi lebar teritisan demi menjaga kesan minimalis dan proporsi bangunan secara keseluruhan. Memang hal ini menimbulkan konsekuensi terhadap desain fasad yang lebih menarik dan proporsional namun tidak fungsional. Maka dari itu diperlukan toleransi yang menyeluruh agar bangunan tetap terjaga nilai estetisnya tanpa meninggalkan fungsinya.

\section{SARAN}

Bagi para pengembang perumahan atau arsitek harus lebih berhati-hati dalam mendesain shading devices. Fungsi, teknis dan estetika shading devices harus secara bersamaan diaplikasikan. Hal yang mendasar adalah mengutamakan untuk menghindari hal-hal negatif yang akan ditimbulkan dari desain shading devices ketimbang mengambil manfaatnya. Alternatif desain shading devices yang berbentuk kisi-kisi horisontal sebagai alternatif solusi.

\section{DAFTAR PUSTAKA}

Frick, Heinz. 1984. Rumah Sederhana. Yogyakarta: Kanisius

Frick, Heinz. 1991. Arsitektur dan Lingkungan. Yogyakarta: Kanisius

Frick, Heinz. 1998. Dasar-dasar Arsitektur Ekologis. Yogyakarta: Kanisius

Lippsmeier, George. 1994. Bangunan Tropis. Jakarta: Erlangga

Mangunwijaya, Y.B. 1997. Pengantar Fisika Bangunan. Yogyakarta: Djambatan. 
Tangoro, Dwi. 2000. Utilitas Bangunan. Jakarta: Universitas Indonesia Press.

Kamus Besar Bahasa Indonesia, Departemen Pendidikan dan Kebudayaan, 1999.Penerbit Balai Pustaka,

Konsep Dasar Design Tritisan - Home Design and Ideas http://www. hdesignideas. com /2010/12/ konsep-dasar-design-tritisan.html\#ixzz2xqID6Rjl

http://himaartra.wordpress.com

http://id.wikipedia.org

http://ithetdjaya.blogspot.com/2012/06/konsep-bangunan-tropis-di-indonesia.html

http://kagama.fk.ugm.ac.id

http://www.bumata.co.id

http://www.desaininterior.net

https://firmanirmansyah.wordpress.com/category/sustainability 